This is a pre-print of an article published in Environmental processes (Ed. Springer). The final authenticated version is available online at:

DOI 10.1007/s40710-016-0161-3

(c) 2016. This manuscript version is made available under the "All rights reserved" license 


\section{Glutamic Acid Independent Production of Bioflocculants by Bacillus subtilis UPMB13}

2 Zufarzaana Zulkeflee ${ }^{1,5}$, Zulkifli H. Shamsuddin ${ }^{2}$, Ahmad Zaharin Aris ${ }^{3}$, Mohd KamilYusoff ${ }^{4}$, Dimitrios

3 Komilis $^{5 *}$, and Antoni Sánchez ${ }^{5}$

4

$5{ }^{1}$ Department of Environmental Sciences, Faculty of Environmental Studies, Universiti Putra Malaysia,

6 43400, UPM Serdang, Selangor, Malaysia

$7 \quad{ }^{2}$ Department of Land Management, Faculty of Agriculture, Universiti Putra Malaysia, 43400, UPM

8 Serdang, Selangor, Malaysia

$9{ }^{3}$ Environmental Forensics Research Centre, Faculty of Environmental Studies, Universiti Putra Malaysia,

1043400 UPM Serdang, Selangor, Malaysia.

$11{ }^{4}$ UPM Consultancy and Services Sdn. Bhd., Universiti Putra Malaysia, 43400, UPM Serdang, Selangor,

12 Malaysia

$13{ }^{5}$ Composting Research Group, Department of Chemical Engineering, Escola d'Enginyeria, Universitat

14 Autònoma de Barcelona, 08913-Bellaterra (Cerdanyola del Vallès), Barcelona, Spain

15

16 Dimitrios Komilis, Ph.D (*Corresponding author)

17 Tel.: $+34-935811019$

Fax: +34- 935812013

18 Email: dimitrios.komilis@uab.cat

19

20 Acknowledgements This research has been funded by the Spanish Ministerio de Economia y

21 Competitividad (project CTM2015-69513-R). Dimitrios Komilis thanks Techniospring for the financial 22 support. 
24 Abstract Bacillus subtilis UPMB13 was found to be an L-glutamic acid independent producer of extracellular polymeric substances (EPS) with bioflocculation properties. Optimum production of the

26 bioflocculant was found to be at the early stage of cell propagation of $24-72 \mathrm{~h}$ of fermentation. At a

27 limited nutrient input of $100 \mathrm{~mL}$ tryptic soy broth, the flocculating activities were found to be negatively

28 correlated $(p<0.01)$ with growth as it continued to decline after $72 \mathrm{~h}$, while cell growth proliferated

29 further. Ample nutrient supply may prolong bioflocculant production with flocculating activities of $90 \%$

30 and higher, while excess oxygen supply may promote rapid growth that can lead to poor flocculation due

31 to the re-use of the bioflocculant as a substitute for food during starvation. Bioflocculant production

32 occurred at best at $25-30^{\circ} \mathrm{C}$ incubation temperature and at the initial $\mathrm{pH}$ medium of 7 to 8 . The

33 bioflocculant was proven to be extracellularly produced as the broth and the supernatant possessed the

34 ability to flocculate the suspended kaolin particles. Bioflocculant productions by UPMB13 were

35 hereditarily stable among succeeding progenies hence, proving genetic competency. About $0.90 \mathrm{~g}$ of

36 purified bioflocculant were collected from $1 \mathrm{~L}$ culture broth of UPMB13 under the optimized

37 fermentation conditions.

38

39 Keywords: Extracellular polymeric substance (EPS); biopolymer; $\gamma$-PGA; de-novo; kaolin assay

40

41 


\section{Introduction}

43 Flocculation is a process of agglomerating suspended particles aided by compounds known as flocculants

44 commonly used in water treatment applications (Devesa-Rey et al. 2012). Among these flocculants,

45 bioflocculants have been identified as the emerging alternative to the conventional chemical flocculants

46 due to their biodegradability and environmentally benign characteristics (Muthulakshmi et al. 2013).

47 Bioflocculants are essentially extracellular polymeric substances (EPS) synthesize mostly by bacteria as

48 they are ubiquitous in nature.

49 Production of biopolymeric compounds by bacterial strains could be unpredictable even under

50 rigorously maintained culture conditions (Bajaj and Singhal 2011a). Stressful culture conditions may

51 induce and improve extracellular polymeric substances production by microorganisms ( $\mathrm{Yu}$ et al. 2015).

52 However, definition of stressful culture conditions are species dependent and may vary for different

53 microorganisms. Salehizadeh and Yan (2014), reviewed on the production of biopolymeric flocculants by

54 microorganisms and stressed that the major criteria influencing bioflocculant performances are culture

55 conditions, including but not limited to culture time, initial $\mathrm{pH}$ and temperature, aeration rate, shaking

56 speed and ionic dependency. Optimization of these factors was proven to enhance the yield, quality and

57 the performances of the bioflocculants produced.

58 One of the most widely studied EPS produced by B. subtilis strains is the poly- $\gamma$-glutamic acid

59 ( $\gamma$-PGA) (Bajaj and Singhal 2011a). $\gamma$-PGA productions typically rely on the input of L-glutamic acid

60 supplement in the culture media. Some exceptional cases reported on $\gamma$-PGA production in the absence of

61 any glutamic acid additions (Zhang et al. 2012). Notably, not all $\gamma$-PGA produced were reported as

62 potential bioflocculants.

63 This paper discusses the production of a novel bioflocculant by a locally isolated rhizobacterium;

64 B. subtilis UPMB13. It aims to i) optimize factors which affect the growth and bioflocculant production

65 by the strain, ii) determine the distribution of the bioflocculant produced in different culture components,

66 and iii) determine genetic competency of UPMB 13 in bioflocculant production. All factors will provide

67 thorough consideration for determining the optimum culture conditions for continuous production of high

68 performing bioflocculants by $B$. subtilis UPMB13 for future studies in suspended solids treatment

69 applications. 


\subsection{Bioflocculant-producing bacteria}

72 B. subtilis UPMB13, isolated from oil-palm root, obtained from the culture collection of the Soil

73 Microbiology Laboratory, Department of Land Management, Universiti Putra Malaysia (Amir et al. 2003;

74 Zulkeflee et al. 2012) was selected based on the morphological characteristics of mucoid and ropy

75 colonies produced when grown on tryptic soy agar (TSA). These characteristics were used as basic

76 identification for potential bioflocculant-producing bacteria (Wong et al. 2012). The strain was verified

77 using Basic Local Alignment Search Tool (BLAST) program analysis based on the 16S ribosomal

78 ribonucleic acid (rRNA) gene sequencing and through biochemical identification test (BBL Crystal

79 Gram-Positive ID System) which proved the strain as B. subtilis at $99 \%$ similarity.

80 Batch cultures of B. subtilis UPMB13 in tryptic soy broth (TSB) were prepared to produce the

81 bioflocculants in broth form. About $50 \mathrm{~mL}$ seed culture of UPMB13 in TSB were prepared and incubated

82 for $24 \mathrm{~h}$ on an orbital shaker ( $150 \mathrm{rpm}$ ) at room temperature. Centrifuged cells (4000 rpm for $10 \mathrm{~min}$ )

83 from the seed culture were then washed three times with phosphate buffer solution (PBS) and once with

84 sterile TSB before inoculation into a fresh $100 \mathrm{~mL}$ TSB and incubated again. Viscous TSB bearing the

85 strain attained indicates bacterial growth and bioflocculant production in the culture. The culture broths

86 were then used directly as the bioflocculant source in the flocculation assays (Aljuboori et al. 2013).

\section{$87 \quad 2.2$ Flocculation assay}

88 Flocculation assays using kaolin clay as the suspended particle were conducted according to the methods

89 described elsewhere (Zulkeflee et al. 2012). The flocculation activities were expressed in percentage

90 clarity of the upper phase of the kaolin suspensions after treatment by the bioflocculant and by visual

91 assessment; either present or absent, of the kaolin flocs formed stimulated by the presence of the

92 bioflocculant

93

$94 \quad 2.3$ Production factors

\subsubsection{L-glutamic acid dependency}


96 Requirement for additional L-glutamic acid supplement for bioflocculant production by UPMB13 were

97 determine by preparing batch cultures of $100 \mathrm{~mL}$ TSB with treatments of; L-glutamic acid (LGA) at 20

98 g/L (Bajaj and Singhal 2011b), L-glutamic acid and citric acid (CA) at $10 \mathrm{~g} / \mathrm{L}$ (Chen et al. 2005), and

99 solely TSB as the control treatment. All cultures with respective treatments were incubated on an orbital

100 shaker at $130 \mathrm{rpm}$ for $48 \mathrm{~h}$ at $25^{\circ} \mathrm{C}$.

$101 \quad$ 2.3.2 Timeline of bioflocculant production

102 Optical density measurements with a spectrophotometer at $660 \mathrm{~nm}$ were conducted to determine the

103 growth of UPMB13 for 5 days. Percentage flocculating activities of the bioflocculants produced by

104 UPMB13 were measured every $6 \mathrm{~h}$ until $78 \mathrm{~h}$, followed by 12 hourly intervals until $120 \mathrm{~h}$ of incubation.

$105 \quad$ 2.3.3 Effect of culture medium ratio on bioflocculant production

106 Batch cultures of UPMB13 in varying volume of TSB (100 mL, $250 \mathrm{~mL}$ and $500 \mathrm{~mL})$ were prepared by

107 inoculating $1 \mathrm{~mL}$ of the seed culture into each respective volume of TSB. Percentage flocculating activity

108 measurements were done at 12 hourly intervals for $120 \mathrm{~h}$.

$109 \quad$ 2.3.4 Effect of incubation speed on bioflocculant production

110 Oxygen fluxes were introduced by means of varying incubation speed on an orbital shaker. Five speeds

111 were selected: 100, 150, 200, 250 and $300 \mathrm{rpm}$. Percentage flocculating activities were measured every 24

$112 \mathrm{~h}$ for three days to observe the effect on bioflocculant production.

$113 \quad$ 2.3.5 Effect of initial $\mathbf{p H}$ and incubation temperature on bioflocculant production

114 The initial $\mathrm{pH}$ of the culture media, adjusted with either $\mathrm{HCl}(1 \mathrm{~N})$ or $\mathrm{NaOH}(1 \mathrm{~N})$, were prepared for $\mathrm{pH}$

$1155.0,6.0,7.0$ and 8.0 (Su et al. 2012). Observations of the flocculating performances were done directly

116 after $24 \mathrm{~h}$ to avoid further $\mathrm{pH}$ changes. Two ranges of incubation temperature were selected, namely; 25-

$11730^{\circ} \mathrm{C}$ (Patil et al. 2009) and $37-40^{\circ} \mathrm{C}$ (Bajaj and Singhal 2011b) provided by an incubator shaker.

118 Percentage flocculating activities were measured at 24, 48, 72 and $96 \mathrm{~h}$ of incubation.

119 
121 The source of bioflocculant produced among the culture components; broth, cell and supernatant, was

122 determined. The cultured cells and cell-free supernatant were separated from the cultured broth by

123 centrifugation at $4000 \mathrm{rpm}$ for $10 \mathrm{~min}$. The supernatant was then removed and put aside as the

124 bioflocculant source for the cell-free supernatant. The centrifuged cells were washed with phosphate

125 buffer solution ( $0.85 \%)$ to create a cell suspension and again centrifuged before serving as the

126 bioflocculant source for the cells.

\subsection{Genetic competence of B. subtilis UPMB13}

128 UPMB13 genetic competence for continuous bioflocculant production was investigated. Each

129 representative generation was prepared by sub-culturing TSA plate cultures of UPMB13; with the first

130 generation being the one directly sub-cultured from the parent stock agar, until the $10^{\text {th }}$ generation. Batch

131 cultures of $100 \mathrm{~mL}$ TSB of each generation were then prepared and the percentage flocculating activities

132 were measured.

\section{$133 \quad 2.6$ Extraction and purification of the bioflocculant}

134 The culture broth of UPMB13 was first tested for flocculating activity through the kaolin assay. When the

135 flocculating activity of the culture broth achieved $90 \%$ and above, the culture broth was then centrifuged

136 at $8000 \mathrm{x}$ g for $10 \mathrm{~min}$ at $4^{\circ} \mathrm{C}$ to separate the cells. The remaining supernatant was then added to 2

137 volumes of ice cold ethanol and left overnight at $4^{\circ} \mathrm{C}$ to precipitate the bioflocculant. The precipitated

138 bioflocculant was then collected by centrifugation at $12000 \mathrm{xg}$ for $15 \mathrm{~min}$ at $4^{\circ} \mathrm{C}$ and re-suspended in

139 ultra-pure water. Further impurities were separated via dialysis against ultra-pure water with minimum

140 three times water change in $24 \mathrm{~h}$ at $4^{\circ} \mathrm{C}$. The resulting dialyzed suspension was then lyophilize to collect

141 the pure bioflocculant.

\section{$142 \quad 2.7$ Surface morphology imaging}

143 The surface morphology of the freeze-dried purified bioflocculant was observed using a scanning electron

144 microscope (SEM) Carl Zeiss EVO-MA10 (Canada). The samples attached to carbon stubs were gold-

145 coated (Nwodo and Okoh 2012) twice and examined using the microscope at an accelerating voltage of 
$14620.0 \mathrm{kV}$. Additionally, the surface morphology of the kaolin particles both before and after flocculation

147 were also scanned and observed.

\section{$148 \quad 2.8$ Data Analysis}

149 For each experiment, a minimum of three replicates of UPMB13 cultures were prepared. Descriptive

150 statistics for pattern and trend observations were determined with the mean and standard deviation values

151 measured. Significant differences were analyzed through analysis of variance (ANOVA) at 0.05

152 confidence level. Additionally, where applicable, repeated measures ANOVA were used for data

153 measured repeatedly in a timely basis.

154

1553 Results and Discussion

$156 \quad 3.1$ L-glutamic acid independent production of bioflocculants

157 Both L-glutamic acid and the citric acid inhibited UPMB13 growth, as the culture broths with the

158 supplements were observed to be clear and translucent after $48 \mathrm{~h}$ of incubation, suggestive of the absence

159 of bacterial growth. In comparison, the control treatment without any added supplement were detected to

160 be naturally viscous after $48 \mathrm{~h}$ of incubation (Table 1 ).

161 The upper phase of the treated kaolin suspension with the supplemented broth were observed to

162 be clear, hence producing a measured flocculating activities of $71.7 \%$ and $27.7 \%$ for the LGA and the

163 LGA+CA treatment, respectively. However, no floc formation was detected in both treatments (Table 1).

164 In contrast, the control TSB media induced flocs formation with percentage flocculating activities

165 measured at $81.7 \%(p<0.05)$. Charge de-stabilization of the kaolin particles might occur in the treated

166 system by the LGA and LGA+CA treatments which explains the percentage flocculating activities

167 measured, despite the absence of the bioflocculant.

168 Productions of $\gamma$-PGA by B. subtilis strains are usually L-glutamic acid dependent, while L-

169 glutamic acid independent strains were described to be relatively unknown and thus less reported (Shih

170 and Van 2001). Some of the L-glutamic acid independent bacteria reported to produce $\gamma$-PGA through the

171 de novo production pathway (without supplement) includes B. subtilis TAM-4 (Ito et al. 1996), B. subtilis

172 C1 (Shih et al. 2005) and B. subtilis C10 (Zhang et al. 2012). Among the studies on the production of $\gamma$ - 
173 PGA by B. subtilis strains that were reported as bioflocculants (Yokoi et al. 1995; Yokoi et al. 1996; Wu

174 and Ye 2007; Wang et al. 2008; Bajaj and Singhal 2011b; Bhunia et al. 2012) none were de novo

175 producers of $\gamma$-PGA. Other $\gamma$-PGAs produced through de novo pathways (Ito et al. 1996; Shih et al. 2005;

176 Zhang et al. 2012) have not been reported as potential bioflocculants. In two rare cases, $\gamma$-PGA had been

177 reported to be produced by Bacillus strains either with or without (de novo) the presence of glutamic acid

178 (Mahmoud 2006; Xu et al. 2005). Therefore, B. subtilis UPMB13 is considered a novel de novo producer

179 of bioflocculants as compared to other cases reported in the literature.

180 Production of EPS by B. subtilis strains has been reported to co-dependently rely on citric acid

181 apart from the L-glutamic acid supplement (Bajaj and Singhal 2011a). Naturally, B. subtilis strains can

182 utilize citric acid as an organic acid carbon source for growth. However, UPMB13 were notably different

183 as citric acid supplement inhibited its growth. Xu et al. (2005) reported similarly for the strain B. subtilis

184 NX-2 which could not incorporate citric acid during growth for $\gamma$-PGA production.

185 Hence, B. subtilis UPMB13 was concluded to be a de novo producer of bioflocculants in the

186 absence of L-glutamic acid or citric acid supplements during growth.

\section{$187 \quad 3.2$ Bioflocculant production during growth}

188 Time course for bioflocculant productions by B. subtilis UPMB13 are as depicted in Figure 1.

189 Bioflocculant presence at the early stage of UPMB13 growth was reflected by the $87.2 \%$ flocculating

190 activities measured and visible flocs formation observed at $24 \mathrm{~h}$ of incubation. The flocculating activities

191 maintained above $80 \%$ between $24-72 \mathrm{~h}(p>0.05)$. This suggests that bioflocculant production by

192 UPMB13 occurred parallel to its logarithmic growth rate. However, between $78 \mathrm{~h}$ to $120 \mathrm{~h}$, decrements in

193 flocculating activities were observed, although UPMB13 growth continued to proliferate. The relationship

194 between growth of UPMB13 and bioflocculant production was analyzed using Pearson Product Moment

195 correlation. There is a strong negative relationship $(R=-0.787)$ between flocculating activities of the

196 bioflocculant with growth $(p<0.01)$.

197 Okaiyeto et al. (2015) reported that the decrease in flocculating activities after $72 \mathrm{~h}$ of incubation 198 could be due to deflocculating enzymes excreted by the strain during death phase. However, in this study, 199 the growth of UPMB13 was observed to be maintained up to $120 \mathrm{~h}$ while flocculating activities were 200 declining. Therefore, it was hypothesized that the limited nutrient supplied (100 $\mathrm{mL})$ had led to the uptake 
201 of the bioflocculant already present in the culture by the cells as alternative food for growth, while

202 productions of new bioflocculants were inhibited by the stressful conditions created by the scarcity of the

203 food. This theory was proven by the results in the next section.

$204 \quad 3.3$ Effect of culture media ratio on bioflocculant production

205 Consumption of the bioflocculants excreted into the culture media as substitute food source for growth

206 was hypothesized to be the reason for the low flocculating performances observed in the later growth

207 stage in Figure 1. This theory was further tested by varying the ratio of culture media used to the

208 inoculum and the results are as portrayed in Figure 2.

209 Both the $250 \mathrm{~mL}$ and $500 \mathrm{~mL}(p>0.05)$ cultures have significantly higher flocculating

210 performances as compared to the $100 \mathrm{~mL}$ culture of UPMB13 $(p<0.05)$ after prolonged fermentations.

211 With ample nutrients provided by the $250 \mathrm{~mL}$ and $500 \mathrm{~mL}$ culture, bioflocculant productions by

212 UPMB13 had sustained until the $120 \mathrm{~h}$ as the percentage flocculating activities measured remained

213 around $90 \%$. Contradictorily, the $100 \mathrm{~mL}$ culture experienced the normal decrease in flocculating

214 performances with prolonged growth. Hence, it was proven that the bioflocculants already present in

215 culture media excreted earlier were being taken up by the strain to support further growth while no new

216 bioflocculants were being produced in the stressful conditions of limited nutrients. It was reported by

217 Kimura et al. (2004) that excreted EPS may be a source of food during starvation in the late stationary

218 microbial growth phase.

\section{$219 \quad 3.4$ Effect of oxygen fluxes on bioflocculant production}

220 Biopolymers yield in aerobic microbial processes depends greatly on oxygen fluxes provided through

221 agitation and aeration during fermentations (Richard and Margaritis 2003). Figure 3 illustrates the

222 flocculating performances of UPMB13 cultures subjected to different shaking speeds provided during

223 incubation. Flocculating activities $>80 \%(p>0.05)$ were recorded at the optimal incubation speeds of 100

224 to $200 \mathrm{rpm}$. Significantly poorer flocculation were observed for cultures agitated at speed higher than 200

$225 \operatorname{rpm}(p<0.05)$.

226 Rapid bacterial growth at higher speed may result in the scarcity of food resources and led to the

227 re-uptake scenario of the excreted bioflocculant as alternative source for food. Excessive oxygen due to 
rapid agitations may also inhibit biopolymeric excretions as concentration of dissolved oxygen affects microbial nutrient absorption and enzymatic reaction for EPS productions (Su et al. 2012). Furthermore,

230 inhibition of production could also be due to the rapid conversion of carbon source to carbon dioxide

231 resulting from the increase in growth and respiration which led to a decrease in biopolymeric productions

232 (Patil et al. 2010.).

\subsection{Effect of initial pH on bioflocculant production}

234 Optimum initial $\mathrm{pH}$ for bioflocculant productions by UPMB13 were at $\mathrm{pH} 7.0$ to 8.0 with percentage

235 flocculating activities measured $>75 \%(p>0.05)$ (Figure 4). Although the growth of UPMB13 were

236 observed to be higher at $\mathrm{pH} 5.0$ and 6, however, flocculating performances measured were significantly

237 lower $(p<0.05)$. The unfavorable acidic nature of the culture media at these $\mathrm{pH}$ ranges might create

238 stressful culture conditions that lower bioflocculant excretions by the strain (Ntsaluba et al. 2013).

239 As bioflocculant production occurs parallel with growth, naturally the optimum $\mathrm{pH}$ for

240 production would be similar to the $\mathrm{pH}$ that induces bacterial growth. However, for UPMB13, the initial

$241 \mathrm{pH}$ of the culture media had more influence on bioflocculant production despite the level of growth.

242 According to Prasertsan et al. (2008), the synthesis of the enzymes that are responsible for EPS excretion

243 are $\mathrm{pH}$ dependent. Furthermore, it was reported that nutrient assimilation and enzymatic response of

244 microorganisms for bioflocculant production may be affected by initial $\mathrm{pH}$ of the culture media

245 (Aljuboori et al. 2013).

\section{$246 \quad 3.6$ Effect of incubation temperature on bioflocculant production}

247 Bioflocculant production were proven feasible in both temperature range with significantly different 248 flocculating performances observed $(p<0.05)$. The $25-30^{\circ} \mathrm{C}$ temperature range was proven optimum for 249 both growth and bioflocculant production. In comparison, at higher temperature range of $37-40^{\circ} \mathrm{C}$, the 250 growth and the flocculating performances of UPMB13 were observed to be inferior (Figure 5).

251 While the growth of UPMB13 fluctuates in the temperature range of $25-30^{\circ} \mathrm{C}$ between $24 \mathrm{~h}$ to 72

$252 \mathrm{~h}$, sustained bioflocculant productions were observed, reflected by the $>70 \%$ percentage flocculating

253 activities measured throughout the assay. In contrast, the flocculating activities of UPMB13 grown at 37-

$25440^{\circ} \mathrm{C}$ decreases with time although its growth proliferated towards the end of the test. This suggested that 
255 the available bioflocculant produced might be consumed back as food substitute that induces growth and

256 thus, lowered the flocculating performances.

257 Optimum growth temperatures for B. subtilis were reported to be at $30-37^{\circ} \mathrm{C}$ with the minimum

258 temperature of $18^{\circ} \mathrm{C}$ and the maximum at $43^{\circ} \mathrm{C}$ (Korsten and Cook 1996). However, for the purpose of

259 bioflocculant production, it was concluded that the optimum temperature range for UPMB13 was 25-

$260 \quad 30^{\circ} \mathrm{C}$

\subsection{Distribution of flocculating abilities by different culture parts}

262 Distribution of flocculating abilities by separated culture parts reflects production source and determines

263 the capacity of each part to be extracted and further purified (Liu and Cheng 2010). Naturally,

264 bioflocculants productions by microorganism can be cellularly bounded or excreted extracellularly as

265 slimes (Subramanian et al. 2009). Therefore, distribution of flocculating activities by different culture

266 parts of UPMB13 was investigated (Figure 6).

267 High flocculating activities around $89 \%$ can be observed by both the culture broth and the cell-

268 free supernatant ( $p>0.05)$ with visible flocs formed. In comparison, the cells' flocculating activities were

269 significantly lower at only $39.4 \%(p<0.05)$, with no flocs formation observed. Charge destabilizations by

270 the cation supplied may explain the percentage flocculating activities achieved by the cells apart from the

271 residual bioflocculant activities that may adhered to the cell surfaces (Wei et al. 2008).

272 The results obtained proved that the bioflocculants are extracellularly produced by UPMB13 into

273 the surrounding broth, exhibited by the cell-free supernatant similarly. Hence, the cell-free supernatant

274 was chosen as the bioflocculant source for the extraction and characterization of the bioflocculant.

\section{$275 \quad 3.8$ Genetic competence for continuous bioflocculant production}

276 UPMB13 was proven to be genetically competence for continuous production of high performing

277 bioflocculants as the ability to produce the bioflocculants persist up to its $10^{\text {th }}$ generation progeny (Figure

278 7).

279 Percentage flocculating activities measured for each generation fluctuated and maintained above

$28080 \%(p>0.05)$ with an exception of the $10^{\text {th }}$ generation, where a slight $9 \%$ decrease can be seen compared 
to the highest measured performance at $86.9 \%(p<0.05)$. Visual assessment of flocs formation were also positive for all generations. expression of polysaccharides by the strain (Dierksen et al. 1997), whereby these characteristics are major contributors to bioflocculability. Furthermore, Shih and Wu (2009) reviewed that some B. subtilis strains have different genetic competency in EPS production. For instance, B. subtilis subsp. (natto) had been reported to be genetically incompetent in continuous production of $\gamma$-PGA. In other reported studies genetic incompetency in bioflocculant production could be overcome through ion implantation (Peirui et al., 2008).

Hence, based on the results it was proven that UPMB13 has the genetic competence in bioflocculant production even after incessant sub-culturing processes.

\subsection{Microscopic images of purified bioflocculant and bioflocculation}

293 From the optimum cultural conditions determined above, fermentation of $1 \mathrm{~L}$ batch cultures were

294 prepared to extract the bioflocculant at its best measured performance based on the kaolin assays. About

$2950.90 \mathrm{~g}$ of purified bioflocculant can be collected from $1 \mathrm{~L}$ culture of UPMB13 in TSB.

296 Figure 8a shows the image of the purified bioflocculant produce by UPMB13, while Figure 8b

297 and Figure 8c display the microscopic images of the kaolin particles both before and after treated by the

298 bioflocculant, respectively. The purified bioflocculant (Figure 8a) appeared to be fibrous with smooth

299 globular structures. These are the typical attributes of $\gamma$-PGA as observed by Yang (2011).

300 The un-flocculated kaolin particles (Figure 8b) are scattered, dispersed and smaller in nature,

301 while the flocculated kaolin particles (Figure 8c) were observed to be clumped together and larger in

302 comparison. According to a review by Maximova and Dahl (2006), aggregated particles formed through

303 induced polymeric flocculations and salt coagulations can be in the form of either loose or compact

304 structures. Aggregates formed in a system with high salts concentrations with added polymeric bridging

305 are loose in nature while those formed from the low coagulant concentration with added shear during

306 bridging lead to the formation of compact aggregate structures. Therefore, referring back to Figure $8 \mathrm{c}$, it

307 can be confirmed that the flocculated kaolin particles portrayed the properties of a compact aggregated 
308 structures which were formed through the induced polymeric bridging of UPMB13 bioflocculant with

309 applied shear and minimal cationic aid.

310 Similar observation was also reported by Nwodo et al. (2014), whereby the bioflocculated kaolin

311 particles formed tightly weaved continuous structures with no evident spacing observed between the

312 particles. Observations of these clumped, flocculated kaolin particles proved the binding and bridging

313 treatment induced by the bioflocculant (Cosa et al. 2013).

\section{Conclusions}

315 Extracellular de novo synthesis (L-glutamic acid independent) of bioflocculants by B. subtilis UPMB13

316 were found to occur at an early logarithmic growth phase of 24-72 h of fermentation. Bioflocculant

317 production was found to be negatively correlated with growth at a limited supply of $100 \mathrm{~mL}$ of tryptic soy

318 broth media. Productions of high performing bioflocculants may be prolonged and sustained with optimal

319 fermentation conditions of sufficient nutrients provided and suitable oxygen level supplied. Proliferation

320 of bacterial growth occur at best at $25-30^{\circ} \mathrm{C}$ and at the optimum $\mathrm{pH} 6$ while $\mathrm{pH} 7.0$ was more preferable

321 for early bioflocculant productions. Bioflocculant production through submerged fermentation of $B$.

322 subtilis UPMB13 was proven feasible based on its genetic competency in continuous production of high

323 performance bioflocculant. The results of the research can be useful in water treatment applications.

324

325 Acknowledgements This research has been funded by the Spanish Ministerio de Economia y

326 Competitividad (project CTM2015-69513-R). Dimitrios Komilis thanks Tecniospring for the financial 327 support.

References

330 Aljuboori AHR, Idris A, Abdullah N, Mohamad R (2013) Production and characterization of a

Amir HG, Shamsuddin ZH, Halimi MS, Ramlan MF, Marziah M (2003) $\mathrm{N}_{2}$ fixation, nutrient

334 accumulation and plant growth promotion by rhizobacteria in association with oil palm seedlings. 
336 Bajaj I, Singhal R (2011a) Poly (glutamic acid): an emerging biopolymer of commercial interest.

337 Bioresource Technol 102:5551-5561. doi:10.1016/j.biortech.2011.02.047

338 Bajaj I, Singhal R (2011b) Flocculation properties of poly( $\gamma$-glutamic acid) produced from Bacillus

339 subtilis isolate. Food Bioprocess Tech 4:745-752. doi:10.1007/s11947-009-0186-y

340 Bhunia B, Mukhopadhy D, Goswami S, Mandal T, Dey A (2012) Improved production, characterization

341 and flocculation properties of poly $(\gamma)$-glutamic acid produced from Bacillus subtilis. J Biochem

$342 \quad$ Technol 3:389-394.

343 Chen X, Chen S, Sun M, Yu Z (2005) Medium optimization by response surface methodology for poly- $\gamma$ -

344 glutamic acid production using dairy manure as the basis of a solid substrate. Appl Microbiol Biot 69:390-396. doi: 10.1007/s00253-005-1989-Z

346 Cosa S, Ugbenyen AM, Mabinya LV, Rumbold K, Okoh AI (2013) Characterization and flocculation efficiency of a bioflocculant produced by a marine Halobacillus. Environ Technol 34:2671-2679. doi:10.1080/09593330.2013.786104

Devesa-Rey R, Bustos G, Cruz J, Moldes A (2012) Evaluation of non-conventional coagulants to remove turbidity from water. Water Air Soil Poll 223:591-598. doi: 10.1007/s11270-011-0884-8

Dierksen KP, Sandine WE, Trempy JE (1997) Expression of ropy and mucoid phenotypes in Lactococcus lactis. J Dairy Sci 80:1528-1536. doi:10.3168/jds.S0022-0302(97)76082-X

Ito Y, Tanaka T, Ohmachi T, Asada Y (1996) Glutamic acid independent production of poly (y-glutamic acid) by Bacillus subtilis TAM-4. Biosci Biotech Bioch 60:1239-1242. doi:10.1271/bbb.60.1239

Jihong Z, Congbin L (2008) Screening and culture condition optimizing of microbial flocculantproducing bacterium. The 2nd International Conference on Bioinformatics and Biomedical Engineering, Shanghai, IEEE, pp 4409-4412. doi:10.1109/ICBBE.2008.599

Kimura K, Tran LSP, Uchida I, Itoh Y (2004) Characterization of Bacillus subtilis gammaglutamyltransferase and its involvement in the degradation of capsule poly-gamma-glutamate. Microbiol 150:4115-4123. doi:10.1099/mic.0.27467-0

Korsten L, Cook N (1996) Optimizing culturing conditions for Bacillus subtilis. South Afric Avocado Grow Assoc Yearbook 19:54-58.

363 Liu LF, Cheng W (2010) Characteristics and culture conditions of a bioflocculant produced by 

egyptian environments. Journal of Applied Science Research 2:608-612.

Maximova N, Dahl O (2006) Environmental implications of aggregation phenomena: current understanding. Curr Opin Colloid In 11:246-266. doi:10.1016/j.cocis.2006.06.001

Muthulakshmi L, Nellaiah H, Busi S (2013) Production and characterization of a novel bioflocculant from Klebsiella sp. Curr Biot 2:53-58.

Ntsaluba L, Nwodo UU, Mabinya L, Okoh A (2013) Studies on bioflocculant production by a mixed culture of Methylobacterium sp. Obi and Actinobacterium sp. Mayor. BMC Biotechnol 13:1-7. doi:10.1186/1472-6750-13-62

Nwodo UU, Green E, Mabinya LV, Okaiyeto K, Rumbold K, Obi LC, Okoh AI (2014) Bioflocculant production by a consortium of Streptomyces and Cellulomonas species and media optimization via surface response model. Colloid Surface B 116:257-264. doi:10.1016/j.colsurfb.2014.01.008

Nwodo UU, Okoh AI (2012) Characterization and flocculation properties of biopolymeric flocculant (glycosaminoglycan) produced by Cellulomonas sp. Okoh. J Appl Microbiol 114:1325-1337. doi: 10.1111/jam. 12095

Okaiyeto K, Nwodo UU, Mabinya LV, Okoli AS, Okoh AI (2015) Characterization of a bioflocculant

Patil SV, Bathe GA, Patil AV, Patil RH, Salunkea BK (2009) Production of bioflocculant strain by ion implantation and flocculating characteristics of bioflocculants. Plasma Sci Technol

391 Prasertsan P, Wichienchot S, Doelle H, Kennedy JF (2008) Optimization for biopolymer production by Enterobacter cloacae WD7. Carbohyd Polym 71:468-475. doi:10.1016/j.carbpol.2007.06.017 

doi:10.1002/bit.10568

Salehizadeh H, Yan N (2014) Recent advances in extracellular biopolymer flocculants. Biotechnol Adv 32:1506-1522. doi:10.1016/j.biotechadv.2014.10.004

Shih IL, Van YT (2001) The production of poly-( $\gamma$-glutamic acid) from microorganisms and its various applications. Bioresource Technol 79:207-225. doi:10.1016/S0960-8524(01)00074-8

Shih L, Wu JY (2009) Biosynthesis and application of poly ( $\gamma$-glutamic acid). In: Bernd R (ed) Microbial production of biopolymers and polymer precursors: applications and perspectives. Horizon Scientific Press, Norfolk, pp 101-141

Shih IL, Wu PJ, Shieh CJ (2005) Microbial production of a poly( $\gamma$-glutamic acid) derivative by Bacillus subtilis. Process Biochem 40:2827-2832. doi:10.1016/j.procbio.2004.12.009

Su X, Shen X, Ding L, Yokota A (2012) Study on the flocculability of the Arthrobacter sp., an actinomycete resuscitated from the VBNC state. World J Microb Biot 28:91-97. doi: $10.1007 / \mathrm{s} 11274-011-0795-2$

Subramanian SB, Yan S, Tyagi RD, Surampalli RY (2009) Bioflocculants. In: Tyagi RD, Surampalli RY, Yan S, Zhang TC, Kao CM, Lohani BN (eds) Sustainable sludge management. American Society of Civil Engineers, Reston, pp 146-167

Wang X, Zhang Y, Zhong W (2008) Poly- $\gamma$-glutamic acid production by novel isolated Bacillus subtilis

\section{Wei W, Fang M, Xiuli Y, Aijie W (2008) Purification and characterization of compound bioflocculant.}

414 In: The 2nd International Conference on Bioinformatics and Biomedical Engineering, Shanghai, IEEE, pp 1127-1130. doi:10.1109/ICBBE.2008.275

416 Wong YS, Ong SA, Teng TT, Aminah LN, Kumaran K (2012) Production of bioflocculant by

417 Staphylococcus cohnii sp. from palm oil mill effluent (POME). Water Air Soil Poll 223:3775-3781. 418 doi:10.1007/s11270-012-1147-z

419 Wu JY, Ye HF (2007) Characterization and flocculating properties of an extracellular biopolymer $420 \quad$ produced from a Bacillus subtilis DYU1 isolate. Process Biochem 42:1114-1123. 
422 Xu H, Jiang M, Li H, Lu D, Ouyang P (2005) Efficient production of poly( $\gamma$-glutamic acid) by newly

423 isolated Bacillus subtilis NX-2. Process Biochem 40:519-523. doi:10.1016/j.procbio.2003.09.025

424 Yang X (2011) Preparation and characterization of $\gamma$-poly (glutamic acid) copolymer with glycol

425 diglycidyl ether. Procedia Environmental Sciences 8:11-15. doi:10.1016/j.proenv.2011.10.004

426 Yokoi H, Arima T, Hirose J, Hayashi S, Takasaki Y (1996) Flocculation properties of poly $([\gamma]$-glutamic

427 acid) produced by Bacillus subtilis. J Ferment Bioeng 82:84-87. doi:10.1016/0922-338X(96)89461-X

428 Yokoi H, Natsuda O, Hirose J, Hayashi S, Takasaki Y (1995) Characteristics of a biopolymer flocculant

429 produced by Bacillus sp. PY-90. J Ferment Bioeng 79:378-80. doi:10.1016/0922-338X(95)94000-H

430 Yu W, Chen Z, Shen, L, Wang Y, Li Q, Yan S, Zhong CJ, He N (2015) Proteomic profiling of Bacillus

431 licheniformis reveals a stress response mechanism in the synthesis of extracellular polymeric

432 flocculants. Biotechnol Bioeng 9999:1-10. doi:10.1002/bit.25838

433 Zhang H, Zhu J, Zhu X, Cai J, Zhang A, Hong Y, Huang J, Huang L, Xu Z (2012) High-level exogenous

434 glutamic acid-independent production of poly- $(\gamma$-glutamic acid $)$ with organic acid addition in a new

435 isolated Bacillus subtilis C10. Bioresource Technol 116:241-246. doi:10.1016/j.biortech.2011.11.085

436 Zulkeflee Z, Aris AZ, Shamsuddin ZH, Yusoff MK (2012) Cation dependence, pH tolerance, and dosage

437 requirement of a bioflocculant produced by Bacillus spp. UPMB13: flocculation performance

438 optimization through kaolin assays. Sci World J. doi:10.1100/2012/495659

439 
440 Table 1 Growth and flocculating activities of UPMB13 at $48 \mathrm{~h}$ of incubation

\begin{tabular}{lccc}
\hline Media & OD660 & Flocculating activities (\%) & Flocs presence \\
\hline Tryptic soy broth (TSB) & $1.49 \pm 0.05$ & 81.7 & Present \\
& & & Absent \\
TSB + L-glutamic acid (LGA) & $0.04 \pm 0.01$ & 71.7 & Absent \\
TSB + L-glutamic acid and citric & $0.03 \pm 0.01$ & 27.7 & \\
acid (LGA+CA) & & & \\
\hline
\end{tabular}

441

442 
445 Fig. 1 The timeline of bioflocculant production by B. subtilis UPMB13 during growth. Bioflocculant

446 production is reflected by the flocculating activities measured

448 Fig. 2 The effect of different culture media ratio on flocculating activities

450 Fig. 3 The effect of various incubation shaking speed on flocculating performances of UPMB13 at $24 \mathrm{~h}$

451 of incubation. Flocs were present in all treatments.

452

453 Fig. 4 Flocculating activities and growth measured at $24 \mathrm{~h}$ at different initial $\mathrm{pH}$. Flocs were present in all 454 treatments.

455

456 Fig. 5 The flocculating activities of UPMB13 biofloculant at incubation temperature range of $25-30^{\circ} \mathrm{C}$

$457)$ and $37-40^{\circ} \mathrm{C}(\square)$ and the growth at $25-30^{\circ} \mathrm{C}(\Delta)$ and $37-40^{\circ} \mathrm{C}(\mathrm{X})$. Flocs were present in all treatments. 458

459 Fig. 6 The distribution of flocculating abilities by different culture parts. The original culture is

460 represented by the broth. The broth is then centrifuged to separate both the supernatant and the cell

461 component of the culture. Flocs were absent in the cell treatment.

462

463 Fig. 7 Flocculating activities of UPMB 13 up to the $10^{\text {th }}$ culture progenies. Flocs were present in all 464 treatments.

465

466 Fig. 8 SEM images of (a) the purified bioflocculant, (b) un-flocculated kaolin particles, and (c) kaolin 467 particles flocculated with UPMB13 bioflocculant 